\begin{tabular}{|c|c|c|}
\hline publications & J. Chem. Metrol. 15:2 (2021) 152-162 & $\begin{array}{c}\text { journal of chemical } \\
\text { metrology }\end{array}$ \\
\hline
\end{tabular}

\title{
Quantification of antileukemic drug Dasatinib in human plasma: Application of a sensitive liquid chromatographic method
}

\author{
Avani Chokshi 1,*(D), Anuradha Gajjar ${ }^{2}$ (D), Pooja Bhanushali ${ }^{1}$ (D), \\ Pritesh Desai $^{4}$ (D) \\ Ramanbhai Patel College of Pharmacy, Charotar University of Science and Technology, \\ CHARUSAT Campus, Changa - 388421, Anand, Gujarat, India \\ L M College of Pharmacy, Navrangpura, Ahmedabad 380 009, Gujarat, India \\ Department of Analytical Research, PTC-Moraiya, Zydus Cadila Healthcare Limited, NH 8A, \\ Moraiya-382213, Gujarat, India
}

(Received August 19, 2021; Revised October 05, 2021; Accepted October 06, 2021)

\begin{abstract}
Dasatinib is a tyrosine kinase inhibitor that is approved and prescribed to patients with chronic myelogenous leukemia and Philadelphia chromosome. Present work reports development of reversed-phase high performance liquid chromatographic method for determination of Dasatinib in human plasma and validation of the developed method according to the guidelines provided by European Medicines Agency (EMA). An RP-HPLC method with UV detection and isocratic elution has been developed and validated for analysis of Dasatinib in human plasma over a range of 5-300 ng/mL. Imatinib was used as an internal standard. Both, the drug and the internal standard were separated on the Inertsil $\mathrm{C}_{18}$ column $(150 \mathrm{~mm} \times 4.6 \mathrm{~mm} \times 0.005 \mathrm{~mm})$ using Ammonium Acetate buffer pH 6.4 and acetonitrile at a ratio of $65: 35$ as mobile phase. The flow rate was adjusted to $0.7 \mathrm{~mL}$ min-1. The detection was performed at $310 \mathrm{~nm}$ wavelength. Sample pre-purification was performed through simple protein precipitation using acetonitrile followed by sample collection through centrifugation. The developed method was linear in the range of 5-300 ng/mL with correlation coefficients $\left(\mathrm{r}^{2}\right)$ of 0.995 . The lower limit of quantification for Dasatinib in plasma was $5 \mathrm{ng} / \mathrm{mL}$. The accuracy and precision of the method were well within the acceptable limits of $15 \%$ over the linear range. In general, the developed method is efficient and inexpensive. It is very simple from the extraction of drug from the plasma matrix to the isocratic elution of analytes. From the data, it can be concluded that the developed method is selective, precise and accurate and applicable for the determination of Dasatinib in human plasma samples.
\end{abstract}

Keywords: Dasatinib; human plasma; liquid chromatography; method validation; UV. () 2021 ACG Publications. All rights reserved.

\section{Introduction}

Chronic myeloid leukemia (CML) or chronic granulocytic leukemia (CGL) is the increased and unregulated growth of myeloid cells of the bone marrow. These cells then start to accumulate in the blood, leading to the cancer of the white blood cells. Patients with CML generally show one common genetic

The article was published by ACG Publications

http://www.acgpubs.org/journal/journal-of-chemical-metrology July-December 2021 EISSN:1307-6183

DOI:http://doi.org/10.25135/jcm.64.2108-2174

Available online: October 09, 2021 
abnormality which is known as the Philadelphia chromosome. These types of patients are largely prescribed with the protein tyrosine kinase inhibitor (TKIs) drugs which have drastically improved the survival rate of the patients with CML. Dasatinib is one of the tyrosine kinase inhibitor drugs which is sold under the name SPRYCEL [1,2].

The bio-analytical method is used for quantitation, detection and measurement of the compound of interest (drug) in biological fluids [3]. Bio-analysis is important for drug discovery and study of pharmacokinetic parameters of new drug candidates [4]. Various methods have been reported for quantitative analysis of Dasatinib in plasma either individually or in combination with other anti-cancer drugs [5-24]. Most of the methods reported are coupled with mass detection (LC-MS) which limits the ease of operation and suitability of the mobile phase [8-24]. Two RP-HPLC methods are reported, one with UV detection [5] and one with fluorescence detection [6]. One literature reports spectrophotometric determination of a combination formulation of antileukemic drugs [7]. One of the aims behind the bioanalytical determination of the drug is to find out the concentration of a therapeutic agent at regular time intervals in the biological fluids. This would help to determine the pharmacokinetic parameters of the drug. For this purpose, the method should be capable of determining the lowest possible concentration, accompanied by ease of operation. All the previously reported RP-HPLC or spectrophotometric methods have the higher quantification limits for the analyte of our interest $(100 \mathrm{ng} / \mathrm{mL}$ for HPLC with UV detection, $50 \mathrm{ng} / \mathrm{mL}$ for HPLC with fluorescence detection and $2 \mu \mathrm{g} / \mathrm{mL}$ for spectrophotometric detection). Moreover, Pirro et al. reported that the developed method by them was not sensitive enough to identify the lower plasma concentration of Dasatinib for its therapeutic monitoring as the drug plasma concentration was far below their limit of quantification [5]. With an aim for the development and validation of a simple, rapid, easy and inexpensive method for the detection of Dasatinib in biological samples even at the lowest concentration, the present study was undertaken.

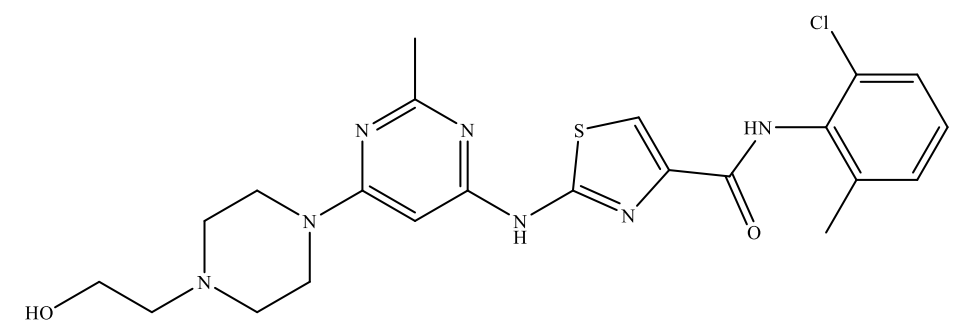

Figure 1. Chemical structure of Dasatinib

\section{Experimental}

\subsection{Chemicals and Reagents}

Dasatinib (drug) and market formulation SPRYCEL tablet (Dasatinib $100 \mathrm{mg}$ ) and internal standard Imatinib were provided by Zydus Cadila Healthcare Limited, Ahmedabad, Gujarat. All chemicals and reagents were purchased from Merck Life Science. Blank human plasma samples were obtained from the blood bank.

\subsection{Standard and Stock Solution}

Working standard solutions of Dasatinib $(10 \mu \mathrm{g} / \mathrm{mL})$ and Imatinib $(10 \mu \mathrm{g} / \mathrm{mL})$ were prepared in methanol. Working stock solution of Dasatinib at the final concentration range of 0.5, 1.5, 1.8, 2.5 and $3.0 \mu \mathrm{g} / \mathrm{mL}$ was prepared by further dilution of Dasatinib stock solution in methanol. All solutions were stored at $-20^{\circ} \mathrm{C}$. 
RP-HPLC determination of Dasatinib in human plasma

\subsection{Calibration Standard and QC Samples}

Calibration standards of Dasatinib were prepared by spiking working standard solutions in blank plasma to a concentration range of 5, 50,180,250 and $300 \mathrm{ng} / \mathrm{mL}$. The quality control (QC) samples were prepared at three concentration levels: low $(15 \mathrm{ng} / \mathrm{mL})$, medium $(150 \mathrm{ng} / \mathrm{mL})$ and high $(210 \mathrm{ng} / \mathrm{mL})$. All solutions were stored at $-20^{\circ} \mathrm{C}$.

\subsection{Sample Solution}

The sample solution was prepared by adding $10 \mu \mathrm{L}$ of working standard solution of Dasatinib in $990 \mu \mathrm{L}$ of blank plasma. The resulting mixture was vortexed for 5 minutes. To the mixture, $1 \mathrm{~mL}$ of acetonitrile was added and centrifuged at $4000 \mathrm{rpm}$ at $5{ }^{\circ} \mathrm{C}$ for 10 minutes. The supernatant was collected and $15 \mu \mathrm{L}$ of $10 \mu \mathrm{g} / \mathrm{mL}$ Imatinib (internal standard) was added.

\subsection{Instrumentation and Chromatographic Conditions}

Chromatographic separation of the drug was performed on Shimadzu HPLC System (LC2010CHT) equipped with autosampler and UV detector. Data was monitored using LC Solution software. Separation was carried out using the Inertsil $\mathrm{C}_{18}$ column $(150 \mathrm{~mm} \times 4.6 \mathrm{~mm} \times 0.005 \mathrm{~mm})$ column. The flow rate was set to $0.7 \mathrm{~mL} / \mathrm{min}$. The auto-sampler was cooled to $5{ }^{\circ} \mathrm{C}$ while the column oven temperature was set to $25^{\circ} \mathrm{C}$. The injection volume was $20 \mu \mathrm{L}$. The measurements were carried out at $310 \mathrm{~nm}$ wavelength for the analysis.

\subsection{Separation of the Drug and Internal Standard}

Isocratic elution technique was employed for the chromatographic separation of Dasatinib and Imatinib using a mobile phase consisting of ammonium acetate buffer ( $\mathrm{pH}$ 6.4) and Acetonitrile in the ratio of $65: 35$.

\subsection{Method Validation}

The method for quantification of Dasatinib in human plasma was validated according to the guidelines issued by the European Medicine Agency (EMA). The validation parameters evaluated include selectivity/ specificity, linearity, accuracy, precision, lower and upper limits of quantification (LLOQ and ULOQ) and matrix stability (benchtop stability and freeze and thaw stability) $[25,26]$.

\subsubsection{Specificity/Selectivity}

The specificity of the method was optimized by analyzing the lowest calibration standard sample $(5 \mathrm{ng} / \mathrm{mL}, \mathrm{n}=6)$ and blank sample in each matrix. A comparison of the area response obtained in the lowest calibration sample of a matrix was used to check the interference in each blank sample.

\subsubsection{Linearity}

Linearity of the method developed for estimation of Dasatinib was performed at five concentration levels $(5,50,180,250$ and $300 \mathrm{ng} / \mathrm{mL})$ in triplicate. A calibration curve was constructed by plotting the peak area ratio of Dasatinib and Imatinib versus concentration. The linear regression equation was calculated for the calibration curve.

\subsubsection{Limit of Quantification}

Six LLOQ $(5 \mathrm{ng} / \mathrm{mL})$ and ULOQ $(300 \mathrm{ng} / \mathrm{mL})$ samples were processed for the extraction of the drug as described above and injected. The concentration of the LLOQ and ULOQ sample against the 
calibration curve were back-calculated and percentage coefficient of variance (\% CV) was found using the formula:

$$
\% \mathrm{CV}=(\mathrm{SD} / \mathrm{Mean}) \times 100
$$

\subsubsection{Accuracy and Precision}

Accuracy and Precision were performed by injecting plasma blank, zero standard, six LLOQ (5 $\mathrm{ng} / \mathrm{mL})$, Six LQC (15 ng/mL), Six MQC (150 ng/mL), Six HQC (210 ng/mL) and six ULOQ (300 ng/mL). Accuracy and precision were analyzed in triplicate for 3 days.

\subsubsection{Matrix Stability}

Bench Top stability was performed at HQC and LQC levels for six replicates each. QC samples for LQC and HQC were prepared and kept at room temperature for $6 \mathrm{hrs}$. Bench Top stability samples were then analyzed along with freshly prepared QC samples in six replicates for each LQC and HQC sample. Freeze and thaw stability was performed at HQC and LQC levels for six replicates. LQC and $\mathrm{HQC}$ QC samples were prepared and frozen at $-70^{\circ} \mathrm{C}$. After complete thawing, samples were again frozen under the same conditions. At each cycle, samples were frozen for at least 12 hours before they are thawed. Freshly prepared QC samples for each LQC and HQC sample were analyzed and compared with the freeze and thaw samples in six replicates. Auto-sampler stability was performed at $5^{\circ} \mathrm{C}$ while long-term stability studies were performed by analyzing the LQC and $\mathrm{HQC}$ samples after freezing them at $-70^{\circ} \mathrm{C}$ for 90 days. All the stability studies were performed in six replicates.

\section{Results and Discussion}

Dasatinib is a small molecule belonging to the class of tyrosine kinase inhibitors [27]. Upon oral administration, it is quickly absorbed from the gastrointestinal tract. Dasatinib, after absorption into the blood, is reported to show high serum protein binding (>90\%) and a very high volume of distribution $[28,29]$. The maximum plasma concentration is attained within 0.5 to 1 hour. The drug is reported to show high variability in intrasubject $\mathrm{T}_{\max }$ and bioavailability [30-33]. It is essential to measure the plasma concentration of the drug at frequent intervals due to the highly variable pharmacokinetic behavior of the drug. All the previously reported bio-analytical methods were either using the hyphenated techniques with mass spectrometric determination or they were less sensitive to measure lower plasma concentration of the drug. Hence, a simple isocratic RP-HPLC analytical method has been developed and validated for the estimation of Dasatinib in human plasma with a run time of 8 minutes. Moreover, the method was developed using the UV detector which can be applied for the intended purpose more economically. The developed method is also proved to measure the low plasma concentration of the drug.

\subsection{Specificity/Selectivity}

The results of the selectivity studies confirm the capability of the developed method to separate the drug and the internal standard without the interference of one another within the selected matrix $[25,26]$. As shown in Figure 2, both Dasatinib and Imatinib are well separated with good peak properties. The system suitability parameters for the developed method are presented in Table 1. 
RP-HPLC determination of Dasatinib in human plasma

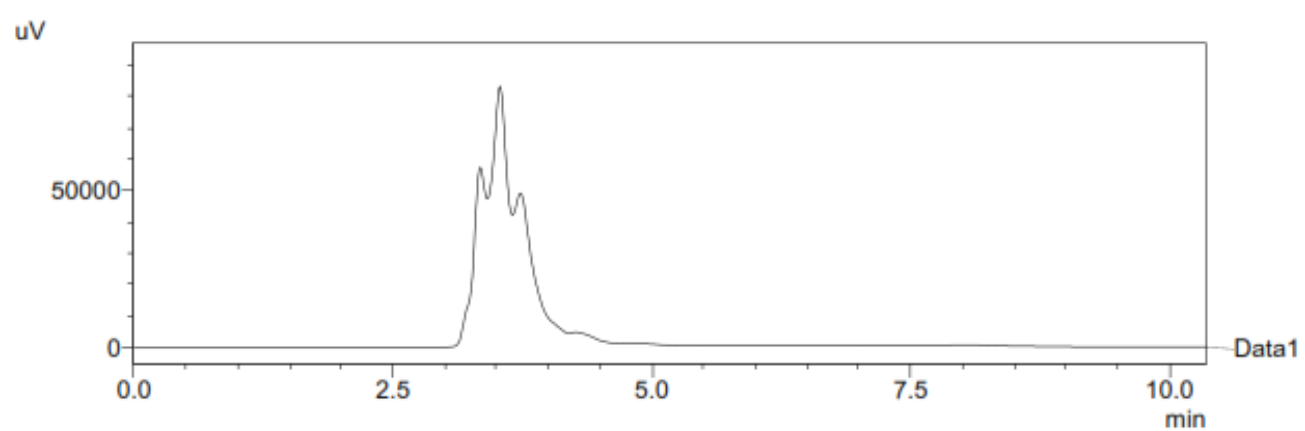

(a)



(b)

Figure 2. (a) Chromatogram of blank plasma; (b) Specificity chromatogram of Dasatinib with internal standard (Imatinib).

Table 1. System suitability parameters for Dasatinib and Imatinib

\begin{tabular}{cccccc}
\hline Analyte & $\begin{array}{c}\text { Retention } \\
\text { time (min) }\end{array}$ & Area & Resolution & Asymmetry & $\begin{array}{c}\text { Theoretical } \\
\text { plates }\end{array}$ \\
\hline $\begin{array}{c}\text { Imatinib } \\
(\mathbf{1 5 0} \mathbf{~ n g} / \mathbf{m L})\end{array}$ & 4.369 & 133725 & - & 0.97 & 2315 \\
$\begin{array}{c}\text { Dasatinib } \\
(\mathbf{5} \mathbf{~ n g} / \mathbf{m L})\end{array}$ & 5.950 & 44612 & 4.09 & 1.30 & 2415 \\
\hline
\end{tabular}

\subsection{Linearity}

Assessment of instrumental response corresponding to the concentration of the analyte may be evaluated by plotting a calibration curve. In general, the calibration range should start with the LLOQ concentration and end with the ULOQ concentration $[25,26]$. The calibration range selected for the analysis was $5-300 \mathrm{ng} / \mathrm{mL}$. The plot was linear with a correlation coefficient $\left(\mathrm{r}^{2}\right)$ of 0.995 . The overlay chromatogram for the calibration range is shown in Figure 3. The back-calculated concentration for the calibration standards was within acceptable limits of $\pm 15 \%$ and at LLOQ, the same was well within acceptable limits of $\pm 20 \%$ for the developed method. 


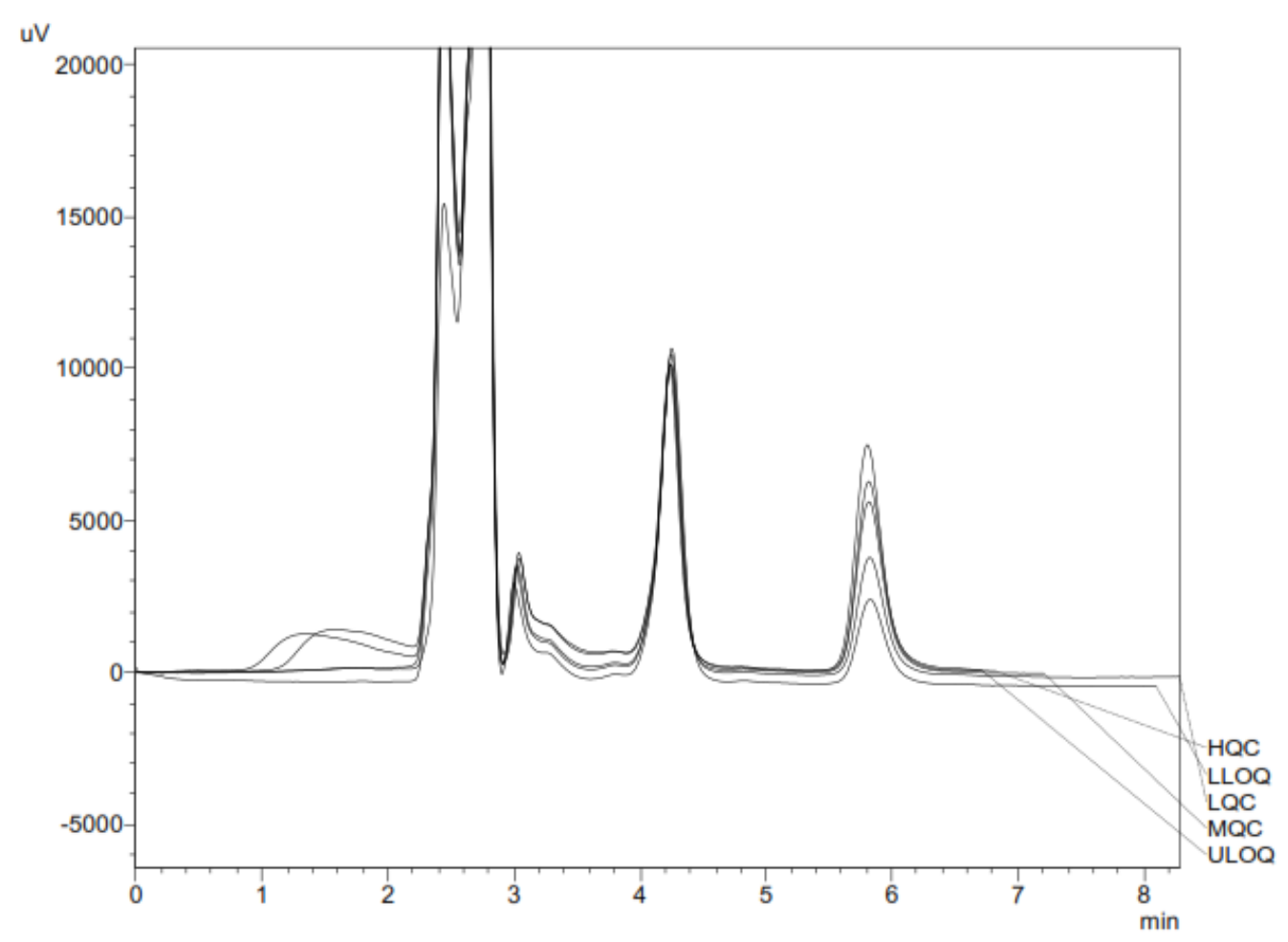

Figure 3. Overlay chromatogram of Dasatinib in the calibration range $(5-300 \mathrm{ng} / \mathrm{mL})$.

\subsection{Accuracy and Precision}

The accuracy of the analytical method provides an idea about the closeness of values between observed concentrations to the nominal concentration, expressed in percentage. The precision of the method describes the closeness of observations for repeated individual measures that are expressed as a coefficient of variance.

Table 2. Accuracy and precision results for determination of Dasatinib in human plasma

\begin{tabular}{|c|c|c|c|c|c|c|}
\hline \multirow{2}{*}{$\begin{array}{l}\text { Nominal } \\
\text { Conc. } \\
(\mathrm{ng} / \mathrm{mL})\end{array}$} & \multicolumn{3}{|c|}{$\begin{array}{l}\text { Within-run Accuracy and Precision } \\
\qquad(\mathrm{n}=6)\end{array}$} & \multicolumn{3}{|c|}{$\begin{array}{l}\text { Between-run Accuracy and Precision } \\
\qquad(n=18)\end{array}$} \\
\hline & $\begin{array}{c}\text { Conc. } \\
\text { determined } \\
(\mathrm{ng} / \mathrm{mL}, \\
\text { mean } \pm \text { SD })\end{array}$ & $\begin{array}{c}\text { Accuracy } \\
(\%)\end{array}$ & $\begin{array}{c}\text { Precision } \\
(\% \mathrm{CV})\end{array}$ & $\begin{array}{c}\text { Conc. } \\
\text { determined } \\
(\mathrm{ng} / \mathrm{mL}, \\
\text { mean } \pm \text { SD })\end{array}$ & $\begin{array}{c}\text { Accuracy } \\
(\%)\end{array}$ & $\begin{array}{c}\text { Precision } \\
(\% \mathrm{CV})\end{array}$ \\
\hline 5 (LLOQ) & $5.71 \pm 0.24$ & 114.20 & 4.20 & $5.21 \pm 0.19$ & 104.20 & 3.67 \\
\hline 15 (LQC) & $16.76 \pm 0.13$ & 111.73 & 0.76 & $16.74 \pm 0.50$ & 111.60 & 2.98 \\
\hline 150 (MQC) & $157.16 \pm 0.83$ & 104.77 & 0.53 & $155.47 \pm 1.09$ & 103.65 & 0.70 \\
\hline 210 (HQC) & $233.33 \pm 1.56$ & 111.11 & 0.67 & $228.02 \pm 2.32$ & 108.58 & 0.80 \\
\hline 300 (ULOQ) & $287.89 \pm 3.41$ & 95.96 & 1.19 & $304.72 \pm 3.92$ & 101.57 & 1.29 \\
\hline
\end{tabular}

The accuracy and precision of the bio-analytical method are determined within a single run and in different runs [25,26]. The results for accuracy and precision for within run and between run at LLOQ, three QC levels (LQC, MQC and HQC) and ULOQ are shown in Table 2. Each sample was prepared in replicates of six for evaluation of accuracy and intra-day precision. For evaluation of inter-day precision, the same process was repeated for three consecutive days. The results at LLOQ and ULOQ are also shown 
RP-HPLC determination of Dasatinib in human plasma

in Table 2. The mean concentration and the coefficient of variation $(\mathrm{CV})$ values (within-run $\mathrm{CV}$ and between-run $\mathrm{CV}$ ) found were within the acceptable limits of $\pm 15 \%$ of the nominal concentration for QC samples and for LLOQ, observed concentration was within the acceptable limits of $\pm 20 \%$ of the nominal concentration.

\subsection{Recovery}

Recovery of Dasatinib was determined for six replicates by comparison of quantification of extracted drug from plasma matrix with those of plasma matrix spiked with drug after extraction at three concentration levels $(50 \mathrm{ng} / \mathrm{mL}, 180 \mathrm{ng} / \mathrm{mL}$ and $300 \mathrm{ng} / \mathrm{mL})$. The percentage recovery at the three concentration levels was found to be $112.1 \%, 104.2 \%$ and $103.7 \%$ respectively with a mean overall recovery of $106.6 \pm 4.7 \%$.

\subsection{Matrix Stability}

Stability studies ensure that the analyte concentration is not affected during various stages of sample preparation, analysis and storage [25,26]. For this reason, a sample matrix is subjected to various temperature conditions ranging from the freezing of sample for storage to the ambient temperature during the laboratory practical. In general, analyte stability in the sample matrix is assessed after several cycles of freezing at the intended storage temperature for a given period followed by thawing at room temperature. The processed sample stability together with the stability during residence time in autosampler is also determined for the sample matrix. The bench-top stability for the sample matrix is performed to evaluate the stability of stock solutions of drug and internal standards. The matrix stability of Dasatinib and internal standard at the above-specified conditions were performed at the LQC and HQC. The results for benchtop stability, freeze and thaw stability, auto-sampler stability at $5^{\circ} \mathrm{C}$ and long-term stability are shown in Table 3. The concentrations calculated for LQC and HQC samples fall within the acceptable limits of $\pm 15 \%$ of nominal concentration.

Table 3. Stability results for Dasatinib in human plasma under different storage conditions

\begin{tabular}{|c|c|c|c|}
\hline Stability condition & $\begin{array}{c}\text { Nominal Conc. } \\
(\mathbf{n g} / \mathbf{m L})\end{array}$ & $\begin{array}{c}\text { Conc. determined } \\
(\mathrm{ng} / \mathrm{mL}, \text { mean } \pm \mathrm{SD})\end{array}$ & $\% \mathrm{CV}$ \\
\hline \multirow[t]{2}{*}{ Auto-sampler stability $\left(5^{\circ} \mathrm{C}\right)$} & 15 (LQC) & $16.3 \pm 0.1$ & 0.67 \\
\hline & 210 (HQC) & $229.5 \pm 6.4$ & 2.77 \\
\hline \multirow{2}{*}{$\begin{array}{c}\text { Benchtop stability (RT for } 6 \\
\text { hr) }\end{array}$} & 15 (LQC) & $16.7 \pm 0.1$ & 0.45 \\
\hline & 210 (HQC) & $227.4 \pm 6.2$ & 2.72 \\
\hline \multirow{2}{*}{$\begin{array}{c}\text { Freeze-thaw stability }\left(-70^{\circ} \mathrm{C}, 2\right. \\
\text { cycles at interval of } 12 \mathrm{hr})\end{array}$} & 15 (LQC) & $16.0 \pm 0.4$ & 2.24 \\
\hline & 210 (HQC) & $241.1 \pm 2.4$ & 1.00 \\
\hline Long term stability $\left(-70^{\circ} \mathrm{C}\right.$ for & 15 (LQC) & $15.7 \pm 0.4$ & 2.77 \\
\hline 3 months) & 210 (HQC) & $234.4 \pm 4.4$ & 1.89 \\
\hline
\end{tabular}

Overall, a simple, rapid, sensitive and economic method was developed for the determination of Dasatinib in human plasma that can be applied for the routine analysis for the intended purpose. The following Table 4 shows the comparison of the results obtained for the present method with already reported RP-HPLC methods. 
Chokshi et al., J. Chem.Metrol. 15:2 (2021) 152-162

Table 4. Result comparison of methods for determination of Dasatinib in human plasma

\begin{tabular}{|c|c|c|c|}
\hline $\begin{array}{c}\text { Method } \\
\text { parameters }\end{array}$ & $\begin{array}{l}\text { Present method (RP- } \\
\text { HPLC with UV } \\
\text { detection) }\end{array}$ & $\begin{array}{l}\text { RP-HPLC with UV } \\
\text { detection [5] }\end{array}$ & $\begin{array}{c}\text { RP-HPLC with } \\
\text { Fluorescence detection } \\
{[6]}\end{array}$ \\
\hline $\begin{array}{c}\text { Drug/ } \\
\text { combination }\end{array}$ & Dasatinib & $\begin{array}{c}\text { Imatinib, } \\
\text { Dasatinib, and Nilotinib }\end{array}$ & Dasatinib \\
\hline Matrix & Human plasma & Human plasma & Rabbit plasma \\
\hline Column & $\mathrm{C}_{18}$ & $\mathrm{C}_{18}$ & $\mathrm{C}_{18}$ \\
\hline Run-time & 8 minutes & 10 minutes & 10 minutes \\
\hline LLOQ & $5 \mathrm{ng} / \mathrm{mL}$ & $100 \mathrm{ng} / \mathrm{mL}^{*}$ & $50 \mathrm{ng} / \mathrm{mL}$ \\
\hline $\begin{array}{l}\text { Internal } \\
\text { standard }\end{array}$ & Imatinib & - & Montelukast \\
\hline
\end{tabular}

\title{
4. Conclusions
}

A simple and =rapid liquid chromatographic method with UV detection was developed for quantification of Dasatinib in human plasma using Imatinib as an internal standard. The developed method has the added advantage of being the conventional RP-HPLC one in contrast to the previously reported hyphenated techniques. Thus, the reported method is much economic and easily applicable. Also, the quantification limit for the present method is $5 \mathrm{ng} / \mathrm{mL}$ which is much lower than the previously reported RP-HPLC methods. This enhances the applicability of the present method for the determination of Dasatinib even at a very low plasma concentration. The developed method was validated and found to be selective for the analyte of interest along with sufficient sensitivity and good reproducibility. The results of the recovery studies indicate the efficiency of the extraction procedure adopted for the analyte. It can be concluded that the developed method can be easily applied for evaluating the pharmacokinetic profile for Dasatinib in human plasma and quantifying minute plasma drug concentration for Dasatinib tablet formulation.

\section{Acknowledgments}

The authors acknowledge Zydus Cadila Healthcare Limited for providing the drug samples. The authors are also grateful to Charotar University of Science and Technology for providing the necessary infrastructure and research facilities.

\author{
Abbreviations \\ RP-HPLC: Reverse Phase High-Performance Liquid Chromatography \\ QC: Quality control \\ LQC: Lowest quality control \\ MQC: Medium quality control \\ HQC: High quality control \\ LLOQ: Lower limit of quantification \\ ULOQ: Upper limit of quantification \\ $\mathrm{CV}$ : Coefficient of variance
}

\section{Supporting Information}

Supporting information accompanies this paper on http://www.acgpubs.org/journal/ journalof-chemical-metrology 
RP-HPLC determination of Dasatinib in human plasma

\section{ORCID}

Avani Chokshi: 0000-0002-6229-4804

Anuradha Gajjar: 0000-0002-2458-4042

Pooja Bhanushali: 0000-0001-9699-844X

Pritesh Desai: 0000-0001-7105-598X

\section{References}

[1] Dasatinib http://chemocare.com/chemotherapy/drug-info/Dasatinib.aspx (Last accessed August 12, 2021).

[2] D. S. Krause and R. A. van Etten (2005) Tyrosine kinases as targets for cancer therapy, New Engl. J. Medicine 353 (2), 172-187.

[3] L. V. Sonawane, B. N. Poul, S. V. Usnale, P. V. Waghmare and L. H. Surwase (2014). Bioanalytical method validation and its pharmaceutical application-a review, Pharm. Anal. Acta, 5 (288), (7 pages). Doi: 10.4172/2153-2435.1000288

[4] M. Vargas and E. Villarraga (2016). Bioequivalence study of two Dasatinib $100 \mathrm{mg}$ formulations in healthy Colombians, J. Bioequival. Bioavail. 9, (4 pages). Doi: 10.4172/jbb.1000315

[5] E. Pirro, S. De Francia, F. De Martino, C. Fava, S. Ulisciani, G. R. Cambrin, S. Racca, G and F. Di Carlo (2011). A new HPLC-UV validated method for therapeutic drug monitoring of tyrosine kinase inhibitors in leukemic patients, J. Chromatogr. Sci. 49(10), 753-757.

[6] M. G. Kassem, E. Ezzeldin, H. M. Korashy and G. A. Mostafa (2013). High-performance liquid chromatographic method for the determination of Dasatinib in rabbit plasma using fluorescence detection and its application to a pharmacokinetic study, J. Chromatogr. B Biomed. Appl. 939, 73-79.

[7] A. S. Abdelhameed, E. S. Hassan,. M. W Attwa, N. S. Al-Shakliah, A. M. Alanazi and H. AlRabiah (2021). Simple and efficient spectroscopic-based univariate sequential methods for simultaneous quantitative analysis of vandetanib, dasatinib, and sorafenib in pharmaceutical preparations and biological fluids, Spectrochim. Acta A Mol. Biomol. Spectrosc. 260, 119987.

[8] S. De Francia, A. D'Avolio, F. De Martino, E. Pirro, L. Baietto, M. Siccardi, M. Simiele, S. Racca, G. Saglio, F. Di Carlo and G. Di Perri (2009). New HPLC-MS method for the simultaneous quantification of the antileukemia drugs Imatinib, Dasatinib, and nilotinib in human plasma, J. Chromatogr. B Biomed. Appl., 877(18-19), 1721-1726.

[9] A Haouala, B. Zanolari, B. Rochat, M. Montemurro, K. Zaman, M. Duchosal, H. Ris, S. Leyvraz, N. Widmer and L. Decosterd, (2009). Therapeutic drug monitoring of the new targeted anticancer agents Imatinib, nilotinib, Dasatinib, sunitinib, sorafenib and lapatinib by LC tandem mass spectrometry, J. Chromatogr. B Biomed. Appl. 877 (22), 1982-1996.

[10] S. Roche, G. McMahon, M. Clynes and R. O’Connor (2009). Development of a high-performance liquid chromatographic-mass spectrometric method for the determination of cellular levels of the tyrosine kinase inhibitors Lapatinib and Dasatinib, J. Chromatogr. B Biomed. Appl., 877(31), 3982-3990.

[11] E. Kralj, J. Trontelj, T. Pajič and A. Kristl (2012). Simultaneous measurement of Imatinib, Nilotinib and Dasatinib in dried blood spot by ultra-high performance liquid chromatography tandem mass spectrometry, $J$. Chromatogr. B Biomed. Appl. 903, 150-156.

[12] A. D'Avolio, M Simiele, S. De Francia, A. Ariaudo, L. Baietto, J. Cusato, C. Fava, G. Saglio, F. Di Carlo and G. Di Perri (2012). HPLC-MS method for the simultaneous quantification of the antileukemia drugs Imatinib, Dasatinib and nilotinib in human peripheral blood mononuclear cell (PBMC), J. Pharm. Biomed. Anal. 59, 109-116.

[13] M. T. Furlong, S. Agrawal, D. Hawthorne, M. Lago, S. Unger, L. Krueger and B. Stouffer (2012). A validated LC-MS/MS assay for the simultaneous determination of the anti-leukemic agent Dasatinib and two pharmacologically active metabolites in human plasma: Application to a clinical pharmacokinetic study, $J$. Pharm. Biomed. Anal. 58, 130-135.

[14] S. R. S. Thappali, K. V. S. Varanasi, S. Veeraraghavan, S. Vakkalanka and M. Khagga (2012). Simultaneous determination of Methotrexate, Dasatinib and its active metabolite N-Deshydroxyethyl Dasatinib in rat plasma by LC-MS/MS: Method validation and application to pharmacokinetic study, Arzneimittelforschung 62 (12), 624-630. 
[15] N. A. Lankheet, M. J. Hillebrand, H. Rosing, J. H Schellens, J. H. Beijnen and A. D. Huitema (2013). Method development and validation for the quantification of Dasatinib, Erlotinib, Gefitinib, Imatinib, Lapatinib, Nilotinib, Sorafenib and Sunitinib in human plasma by liquid chromatography coupled with tandem mass spectrometry, Biomed. Chromatogr. 27 (4), 466-476.

[16] I. Andriamanana, I. Gana, B. Duretz and A. Hulin (2013). Simultaneous analysis of anticancer agents Bortezomib, Imatinib, Nilotinib, Dasatinib, Erlotinib, Lapatinib, Sorafenib, Sunitinib and Vandetanib in human plasma using LC/MS/MS, J. Chromatogr. B Biomed. Appl. 926, 83-91.

[17] M. Birch, P. E. Morgan, S. Handley, A. Ho, R. Ireland and R. J Flanagan (2013). simple methodology for the therapeutic drug monitoring of the tyrosine kinase inhibitors Dasatinib and Imatinib. Biomed. Chromatogr. 27 (3), 335-342.

[18] C. Wen, Q. Zhang, Y. He, M. Deng, X. Wang and J. Ma (2015). Gradient elution LC-MS determination of Dasatinib in rat plasma and its pharmacokinetic study, Acta Chromatogr, 27 (1), 81-91.

[19] J. Zeng, H. lin Cai, Z. Ping-Jiang, Q. Wang, Y. Zhu, P. Xu, X. Lan Zhao (2017). A validated UPLC-MS/MS method for simultaneous determination of Imatinib, Dasatinib and Nilotinib in human plasma, J. Pharm. Anal. 7 (6), 374-380.

[20] A. Wojnicz, B. Colom-Fernández, J. L. Steegmann, C. Muñoz-Calleja, F. Abad-Santos and A. Ruiz-Nuño (2017). simultaneous determination of Imatinib, Dasatinib, and Nilotinib by liquid chromatography-tandem mass spectrometry and its application to therapeutic drug monitoring, Ther. Drug Monit. 39 (3), $252-262$.

[21] Y. He, L. Zhou, S. Gao, T. Yin, Y. Tu, R. Rayford, X. Wang and M. Hu (2018). Development and validation of a sensitive LC-MS/MS method for simultaneous determination of eight tyrosine kinase inhibitors and its application in mice pharmacokinetic studies, J. Pharm. Biomed. Anal. 148, 65-72.

[22] H. M. Maher, N. Z. Alzoman, S. M. Shehata and N. O. Abanmy (2018). Validated UPLC-MS/MS method for the quantification of Dasatinib in plasma: application to pharmacokinetic interaction studies with nutraceuticals in wistar rats. PLoS One, 13 (6), e0199208.

[23] N. Z. Alzoman, H. M. Maher, S. M. Shehata and N. O. Abanmy (2019). UPLC-MS/MS study of the effect of dandelion root extract on the plasma levels of the selected irreversible tyrosine kinase inhibitors Dasatinib, Imatinib and Nilotinib in rats: potential risk of pharmacokinetic interactions, Biomed. Chromatogr. 33 (12), e4674.

[24] S. Yang, X. Zhang, Y. Wang, C. Wen, C. Wang, Z. Zhou and G. Lin (2021). Development of UPLC-MS/MS method for studying the pharmacokinetic interaction between Dasatinib and Posaconazole in rats, Drug Des Develop. Therap. 15, 2171.

[25] Food and Drug Administration, U.S (2018). Bioanalytical method validation guidance for industry, US Department of Health and Human Services, 1-41.

[26] https://www.ema.europa.eu/en/documents/scientific-guideline/guideline-bioanalytical-methodvalidation_en.pdf (Last accessed August 12, 2021).

[27] P. Cohen (2002). Protein kinases - the major drug targets of the twenty-first century? Nat. Rev. Drug Discov. 1 (4), 309-315.

[28] R. Chandani, J. He and F Trabelsi (2017). Atypical pharmacokinetic profiles observed with Dasatinib reference listed drug product in bioequivalence studies. Presented at the AAPS Annual Meeting, San Diego. Available at:https://www.biopharmaservices.com/wp-content/uploads/2018/06/Poster-1-Dasatinib-final-AAPS2017.pdf

[29] L. J. Christopher, D. Cui, C. Wu, R. Luo, J. A Manning, S. J. Bonacorsi, M. Lago, A. Allentoff, F. Y. F. Lee, B. McCann, S. Galbraith, D. P Reitberg, K. He, A. Barros, A. Blackwood-Chirchir, W. G. Humphreys and R. A. Iyer (2008). Metabolism and disposition of Dasatinib after oral administration to humans, Drug Metab Dispos, 36 (7), 1357-1364.

[30] R. Aplenc, S. M. Blaney, L. C. Strauss, F. M. Balis, S. Shusterman, A. M. Ingle, S. Agrawal, J. Sun, J. J. Wright and P. C. Adamson (2011). Pediatric phase I trial and pharmacokinetic study of Dasatinib: a report from the children's oncology group phase I consortium, J. Clin. Oncol. 29 (7), 839-844.

[31] B.M. Squibb (2017). Sprycel (Dasatinib) highlights of prescribing information, Princeton, NJ: Bristol-Myers Squibb. 
RP-HPLC determination of Dasatinib in human plasma

[32] S. Takahashi, M. Miyazaki, I. Okamoto, Y. Ito, K. Ueda, T. Seriu, K. Nakagawa and K. Hatake (2011). Phase I study of Dasatinib (BMS-354825) in Japanese patients with solid tumors, Cancer Sci, 102 (11), 2058-2064.

[33] G. D. Demetri, P. L. Russo, I. R MacPherson, D. Wang, J. A. Morgan, V. G. Brunton, P. Paliwal, S. Agrawal, M Voi and T. J Evans (2009). Phase I dose-escalation and pharmacokinetic study of Dasatinib in patients with advanced solid tumors, Clin. Cancer Res. 15 (19), 6232-6240.



(C) 2021ACG Publications 